\title{
PEMETAAN DATA RECHARGE AIR TANAH DI KABUPATEN SLEMAN BERDASARKAN DATA CURAH HUJAN
}

\author{
Bambang Yuwono ${ }^{(1)}$, Awang Hendrianto Pratomo ${ }^{(2)}$, Heru Cahya Rustamaji ${ }^{(3)}$, \\ Puji Pratiknyo ${ }^{(4)}$, Mochamad Assofa Indera Jati ${ }^{(5)}$ \\ ${ }^{1,2,3,5)}$ Program Studi Teknik Informatika, Fakultas Teknik Industri, \\ UPN “Veteran” Yogyakarta, Jl. Babarsari No. 2, Tambakbayan, Depok Sleman \\ ${ }^{4)}$ Program Studi Teknik Geologi, Fakultas Teknologi Mineral, \\ UPN “Veteran" Yogyakarta, JI. SWK No. 104, Condong Catur, Depok Sleman \\ e-mail: bambangy@gmail.com ${ }^{(1)}$, awang@upnyk.ac.id(2), herucr@gmail.com ${ }^{(3)}$, \\ puji_pratiknyoupn@yahoo.com ${ }^{(4)}$
}

\begin{abstract}
Water is a basic need for humans and other living things. Various sources of water on this earth has formed a system of close interaction with the components of living things in it. Over the years, water resources have changed in terms of both quality and quantity. This can be due to population growth in addition to the natural changes in nature. The more narrow field of water absorption followed by high water consumption causes the supply of ground water reserves can be threatened. So, we need a mapping and ground water recharge calculations to assist in the monitoring of groundwater reserves.

The method used in this research is the Water Balance (keseimbangan air)method. This method is based on any incoming rain water will be equal to the output evapotranspiration and runoff hereinafter this method is applied in the application. Factors affecting groundwater recharge the water balance method is precipitation, evapotranspiration and run off. Information og groundwater recharge is also displayed on the map using Google Map function are related to the database system to produce informative mapsCalculation of groundwater recharge is applied to the daily rainfall data input into the application which then included in the water balance equation method so it can be easy to determine the value of groundwater recharge. Groundwater recharge information can be displayed in the form of mapping, making them easier to understand visually.Based on testing, the highest recharge results of this research on the Kemput station is 1119,5 mm/year with rainfall of $2750 \mathrm{~mm} /$ year. Seyegan and Bronggang station is 1026,25 mm/year with rainfall of $2625 \mathrm{~mm} /$ year. Angin-angin and Prumpung station is $933 \mathrm{~mm} /$ year with rainfall of $2500 \mathrm{~mm} /$ year. Beran and Gemawang station is $839.5 \mathrm{~mm} / \mathrm{year}$ with rainfall of $2375 \mathrm{~mm} / \mathrm{year}$. Plataran station is $808.42 \mathrm{~mm} / \mathrm{year}$ with rainfall of $2333 \mathrm{~mm} / \mathrm{year}$. Godean station is $699.5 \mathrm{~mm} / \mathrm{year}$ with rainfall of $2187 \mathrm{~mm} / \mathrm{year}$ and the lowest at Tirto Tanjungand Santan stastion $560 \mathrm{~mm} /$ year with rainfall of $2000 \mathrm{~mm} /$ year.
\end{abstract}

Key words : GIS, Rainfall, Recharge, Water Balance

\section{Abstrak}

Air merupakan salah satu kebutuhan pokok bagi manusia maupun makhluk hidup lainnya. Berbagai sumber air di muka bumi ini telah membentuk suatu sistem interaksi yang erat dengan komponen makhluk hidup di dalamnya. Seiring perkembangan waktu, sumber daya air telah mengalami perubahan baik dari segi kualitas maupun kuantitas. Hal ini dapat disebabkan oleh pertumbuhan penduduk selain adanya perubahan alam secara alami.Semakin sempit lahan resapan air diikuti konsumsi air yang tinggi menyebabkan persediaan cadangan air tanah dapat terancam. Sehingga diperlukan pemetaan dan perhitungan recharge air tanah untuk membantu dalam pemantauan cadangan air tanah.Metode yang digunakan dalam penelitian ini yaitu metode Water Balance (keseimbangan air). Metode ini didasarkan setiap air hujan yang masuk akan sama dengan keluaran evapotranspirasi dan run off yang selanjutnya metode ini diterapkan dalam aplikasi. Faktor yang mempengaruhi recharge air tanah dalam metode water balance adalah curah hujan, evapotranspirasi dan run off. Informasi recharge air tanah juga 
ditampilkan dalam peta menggunakan fungsi Google Map yang direlasikan dengan database sistem sehingga menghasilkan peta yang informative. Perhitungan recharge air tanah diterapkan dengan proses input data curah hujan harian ke dalam aplikasi yang selanjutnya dimasukan dalam persamaan metode water balance sehingga dapat dengan mudah untuk mengetahui nilai recharge air tanah. Informasi recharge air tanah dapat ditampilkan dalam bentuk pemetaan sehingga lebih mudah dipahami secara visual. Berdasarkan pengujian, hasil recharge tertinggi pada penelitian ini pada Stasiun Kemput yaitu 1119,5 mm/tahun dengan curah hujan $2750 \mathrm{~mm} /$ tahun. Stasiun Seyegan dan Bronggang 1026,25 mm/tahun dengan curah hujan $2625 \mathrm{~mm} /$ tahun. Stasiun Angin-angin dan Prumpung $933 \mathrm{~mm} / \mathrm{tahun}$ dengan curah hujan $2500 \mathrm{~mm} /$ tahun. Stasiun Beran dan Gemawang 839,5 mm/tahun dengan curah hujan $2375 \mathrm{~mm} /$ tahun. Stasiun Plataran 808,42 mm/tahun dengan curah hujan $2333 \mathrm{~mm} /$ tahun. Stasiun Godean 699,5 mm/tahun dengan curah hujan $2187 \mathrm{~mm} /$ tahun dan yang terendah pada stasiun Santan dan Tanjung Tirto 560 mm/tahun dengan curah hujan 2000 mm/tahun.

Kata kunci : SIG, Curah hujan, Recharge, Water Balance

\section{PENDAHULUAN}

Air merupakan salah satu kebutuhan pokok bagi manusia maupun makhluk hidup lainnya. Berbagai sumber air di muka bumi ini telah membentuk suatu sistem interaksi yang erat dengan komponen makhluk hidup di dalamnya. Hubungan ketergantungan di dalam ekosistem bumi akhirnya menempatkan air sebagai bagian yang tak terpisahkan dari setiap komponen makhluk hidup. Terdapat delapan komponen alami sumber daya air, antara lain sungai, pantai, danau, rawa, daerah retensi, mata air, air terjun dan air tanah (Hatala, 2007).

Seiring perkembangan waktu, sumber daya air telah mengalami perubahan baik dari segi kualitas maupun kuantitas. Hal ini dapat disebabkan oleh pertumbuhan penduduk selain adanya perubahan alam secara alami (Hatala, 2007). Pertumbuhan penduduk yang pesat di Indonesia dapat dilihat pada kota-kota besar salah satunya adalah Yogyakarta. Daerah Istimewa Yogyakarta salah satu provinsi besar yang ada di Indonesia ini sudah mengalami pertumbuhan penduduk yang pesat. Salah satu kabupaten di DIY yang telah mengalami kemajuan yang pesat adalah kabupaten Sleman. Kemajuan ini dapat dilihat dari semakin banyaknya properti seperti perindustrian, perhotelan, supermarket, mall dan perumahan penduduk. Semakin padatnya penduduk dapat mengancam keseimbangan dan ketersediaan cadangan air dalam tanah jika pembangunan tidak terkontrol. Semakin sempit lahan resapan air diikuti konsumsi air yang tinggi menyebabkan persediaan cadangan air tanah dapat terancam. Hotel, supermarket dan mall merupakan bangunan vertikal yang membutuhkan jumlah air bersih sangat besar untuk mencukupi kebutuhan air di bangunan tersebut. Untuk mencegah dampak buruk yang disebabkan hal tersebut maka pemerintah membuat kebijakan perizinan pendirian bangunan melalui Dinas Penyediaan Air Baku agar perkembangan pembangunan dapat dikontrol. Pemberian izin pembangunan didasarkan pada hasil pemantauan sumur produksi dan sumur pantau di daerah tertentu. Perlu kesadaran masyarakat agar selalu memantau dan menjaga ketersediaan air di daerahnya agar sumber daya air ini tidak tereksploitasi secara sembarangan.

Sistem informasi yang tepat untuk mengimplementasikan suatu pola cadangan air tanah yang berguna untuk memantau air tanah berupa peta adalah dengan Sistem Informasi Geografis (SIG). Sistem Informasi Geografis merupakan sistem berbasis komputer yang didesain untuk mengumpulkan, mengelola, memanipulasi dan menampilkan informasi spasial (keruangan). Sistem Informasi Geografis mempunyai hubungan geometris dalam arti bahwa informasi tersebut dapat dihitung, diukur dan disajikan dalam sistem koordinat dengan data berupa data digital yang terdiri dari data posisi dan data semantiknya (Yuhana, 2010).

Berdasarkan uraian diatas maka perlu dilakukannya pembangunan sistem informasi mengenai cadangan air tanah. Oleh karena itu pada penelitian ini dibangun sistem informasi berbasis Sistem Informasi Geografis dengan memanfaatkan fungsi-fungsi Google Map API sehingga peta yang dihasilkan berupa peta Google Maps untuk menggambarkan cadangan air tanah di propinsi Yogyakarta kushusnya di daerah Sleman. Penelitian ini diharapkan dapat 
mempermudah dalam perhitungan perkiraan cadangan air tanah di Kabupaten Sleman, memberikan informasi mengenai cadangan air tanah yang mudah dibaca dan dipahami oleh user (user friendly), serta dapat memberikan informasi berupa peta wilayah di Kabupaten Sleman yang diintegrasikan dengan google map API

\section{METODE PENELITIAN}

Metodologi pada penelitian ini menggunakan metode waterfallsebagai pengembangan sistem. Metode waterfall berisi lima tahapan yaitu pengumpulan data, analisis kebutuhan sistem, perancangan sistem, penulisan program (coding) dan pengujian. Tahap pengumpulan data melalui tiga cara yaitu observasi, studi pustaka dan wawancara. Selanjutnya dilakukan analisis sistem untuk mengetahui kebutuhan sistem. Tahap selanjutnya perancangan sistem. Perancangan sisten terbagi atas tiga bagian yaitu perancangn proses, perancangan basis data, perancangan interface. Perancangan sistem menghasilkan Data Flow Diagram (DFD), Entity Relational Diagram(ERD), Relasi Antar Tabel (RAT) dan layer pada peta SIG. Setelah seluruh rancangan terbentuk, selanjutnya dilakukan pengkoden dengan membuat source code sesuai dengan perancangan yang dibuat. Tahap terakhir metode ini yaitu pengujian. Pengujian dilakukan dengan membandingkan hasil penelitian yang berjudul "Pemetaan Dan Perhitungan Recharge Air Tanah Berdasarkan Data Curah Hujan Di Kabupaten Sleman" dengan penelitian yang dilakukan oleh Victor Aleluia de Sousa Vicente (2014) yang berjudul "Cadangan Airtanah Berdasarkan Geometri dan Konfigurasi Sistem Akuifer Cekungan Airtanah Yogyakarta-Sleman, Provinsi Daerah Istimewa Yogyakarta".

\section{HASIL DAN PEMBAHASAN}

Pada penelitian "Pemetaan dan Perhitungan Recharge Air Tanah Berdasarkan Data Curah Hujan Di Kabupaten Sleman" bertujuan memberikan kemudahan dalam perhitungan perkiraan cadangan air tanah di Kabupaten Sleman sehingga informasi yang dihasilkan dapat dengan mudah dipahami oleh pengguna (user friendly) serta memberikan informasi berupa peta wilayah di Kabupaten Sleman yang diintegrasikan dengan google map API. Aplikasi ini memanfaatkan fungsi-fungsi Google Map API, peta yang dihasilkan berupa peta Google Map untuk menggambarkan cadangan air tanah di provinsi Daerah Istimewa Yogyakarta kushusnya di Kabupaten Sleman. Data yang digunakan dalam penelitian ini yaitu data sekunder curah hujan di Kabupaten Sleman, kemudian dari data sekunder ini akan diperoleh nilai recharge air tanah yang sebelumnya diolah menggunakan persamaan berikut :

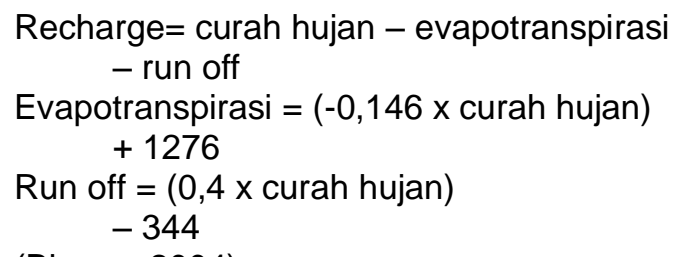

(Bisson, 2004)

Data recharge ini merupakan jumlah air yang masuk ke dalam tanah yang selanjutnya dijadikan hasil perkiraan cadangan air tanah. Perhitungan rechargeairtanah dilakukan dengan metode keseimbangan air (water balance). Penggunaan metode ini didasarkan atas ilmu geologi yang luas, sehingga apabila tidak dibatasi maka penelitian ini akan meluas dan tidak terfokus pada data curah hujan yang digunakan sebagai data utama dalam penelitian ini. Selain itu metode ini menggunakan rumus yang mudah diterapkan ke dalam aplikasi sehingga rumus ini dapat dengan mudah dimengerti secara universal oleh orang yang awam mengenai ilmu Geologi.Metode ini mengasumsikan setiap masukan oleh air hujan akan sama dengan keluaran oleh evapotranspirasi, run off(Ningsih \& Ayuningtyas, 2011). Recharge dapat dihitung dengan mengurangkan curah hujan dengan evapotranspirasi dan run off. Evapotranspirasi disini menggambarkan jumlah air yang hilang karena proses vegetasi tumbuhan sedangkan run off sendiri merupakan air yang mengalir dipermukaan menuju sungai, danau atau rawa.

Berdasakan persamaan rumus di atas, data curah merupakan faktor utama yang akan diproses ke dalam aplikasi. Persamaan tersebut dituliskan ke dalam aplikasi berupa scriptphp yang merupakan sql query. Sql query ini merupakan perintah untuk pemanggilan data curah hujan yang berasal dari database dan sekaligus representasi dari persamaan rumus recharge air 
tanah. Data curah hujan yang digunakan adalah data harian yang diakumulasi selama satu tahun sehingga didapatkan data curah hujan total selama satu tahun. Setelah curah hujan tahunan didapatkan selanjutnya data tersebut diproses ke dalam rumus unuk mendapatkan nilai recharge air tanah. Nilai recharge air tanah akan ditampilkan pada halaman peta air tanah sebagai informasi utama. Dari hasil perhitungan tersebut maka didapatkan data hasil recharge air tanah seperti pada Tabel 1 berikut ini:

Data diatas merupakan data hasil perhitungan recharge air tanah berdasarkan data curah hujan Kabupaten Sleman pada setiap stasiun curah hujan. Berdasarkan data Balai PSDA DIY Kabupaten Sleman memiliki 11 titik stasiun curah hujan. Apabila dilihat dari data di atas dapat diketahui bahwa semakin tingginya curah hujan maka semakin besar pula recharge air tanah yang didapatkan. Hal ini sesuai dengan prinsip metode water balance dimana tingginya curah hujan menunjukkan semakin besarnya air yang akan terserap di dalam tanah, sehingga semakin besar pula simpanan air tanah disuatu tempat.

Bila dibandingkan dengan penelitian yang dilakukan oleh Victor Aleluia de Sousa Vicente (2014) yang berjudul "Cadangan Airtanah Berdasarkan Geometri dan Konfigurasi Sistem Akuifer Cekungan Airtanah Yogyakarta-Sleman, Provinsi Daerah Istimewa Yogyakarta" yang menggunakan metode berbeda seperti pada persamaan di bawah ini :

$\mathrm{RC}=\mathrm{P} \times \mathrm{A} \times \mathrm{Rf} \%$.

[4]

Maka recharge air tanah yang diperoleh dapat ditunjukan seperti pada Tabel 2 berikut ini :

Tabel 1 Data hasil perhitungan recharge air tanah berdasarkan data curah hujan Sleman

\begin{tabular}{|c|l|l|c|c|}
\hline No & $\begin{array}{c}\text { Nama Stasiun Curah } \\
\text { Hujan }\end{array}$ & \multicolumn{1}{|c|}{ Kecamatan } & $\begin{array}{c}\text { Curah hujan } \\
\text { (mm/tahun) }\end{array}$ & $\begin{array}{c}\text { Recharge Air Tanah } \\
\text { (mm/tahun) }\end{array}$ \\
\hline 1 & Angin-angin & Sleman & 2500 & 933 \\
\hline 2 & Prumpung & Ngaglik & 2500 & 933 \\
\hline 3 & Kemput & Turi & 2750 & 1119,5 \\
\hline 4 & Seyegan & Tempel & 2625 & 1026,25 \\
\hline 5 & Bronggang & Ngemplak & 2625 & 1026,25 \\
\hline 6 & Plataran & Ngemplak & 2333 & 808,42 \\
\hline 7 & Beran & Mlati & 2375 & 839,5 \\
\hline 8 & Gemawang & Mlati & 2375 & 839,5 \\
\hline 9 & Santan & Berbah & 2000 & 560 \\
\hline 10 & Godean & Seyegan & 2187 & 699,5 \\
\hline 11 & Tanjung Tirto & Berbah & 2000 & 560 \\
\hline
\end{tabular}

(Sumber : Balai PSDA DIY)

Tabel 2 Data Imbuhan Air Tanah Kabupaten Sleman (Victor Aleluia de Sousa Vicente)

\begin{tabular}{|c|c|c|c|c|c|c|c|c|}
\hline No & Kecamatan & Litologi & Koefisien & Luas & Curah Hujan & $\begin{array}{l}\text { Imbuhan } \\
\text { m3/tahun }\end{array}$ & Imbuhan It/detik & $\mathrm{mm} / \mathrm{tahun}$ \\
\hline 1 & Tempel & Pasir volkanik kasar & 30 & 33.559 .736 & 2.675 & 26.428 .292 & 838 & 802.5 \\
\hline 2 & Turi & Pasir volkanik kasar & 30 & 39.687 .966 & 2750 & 32.742 .572 & 1038 & 825 \\
\hline 3 & Pakem & Pasir volkanik kasar & 30 & 51.284 .863 & 2750 & 42.392 .512 & 1344 & 825 \\
\hline 4 & Cangkringan & Pasir volkanik kasar & 30 & 43.259 .703 & 2625 & 34.067 .016 & 1080 & 787.5 \\
\hline 5 & Ngemplak & Pasir volkanik kasar & 30 & 36.696 .347 & 2333 & 25.683 .773 & 814 & 699.9 \\
\hline 6 & Ngaglik & Pasir volkanik kasar & 30 & 38.289 .488 & 2500 & 28.717 .116 & 910 & 750 \\
\hline 7 & Sleman & Pasir volkanik kasar & 30 & 31.148 .717 & 2500 & 23.361 .537 & 740 & 750 \\
\hline 8 & Seyegan & Pasir volkanik sedang & 25 & 26.705 .273 & 2375 & 15.856 .256 & 502 & 593.75 \\
\hline 9 & Mlati & Pasir volkanik sedang & 25 & 28.277 .655 & 2375 & 16.789 .857 & 532 & 593.75 \\
\hline 10 & Depok & Pasir volkanik sedang & 25 & 33.960 .466 & 2375 & 20.164 .027 & 639 & 593.75 \\
\hline 11 & Berbah & Pasir volkanik sedang & 25 & 23.339 .378 & 2000 & 11.669 .689 & 370 & 500 \\
\hline 12 & Prambanan & Pasir volkanik sedang & 25 & 15.415 .466 & 2000 & 7.707 .733 & 244 & 500 \\
\hline 13 & Gamping & Pasir volkanik sedang & 25 & 23.694 .565 & 2187 & 12.955 .003 & 410 & 546.75 \\
\hline 14 & Godean & Pasir volkanik sedang & 25 & 26.764 .404 & 2187 & 14.633 .438 & 464 & 546.75 \\
\hline 15 & Minggir & Pasir volkanik sedang & 25 & 33.018 .592 & 2187 & 18.052 .915 & 572 & 546.75 \\
\hline 16 & Kalasan & Pasir volkanik sedang & 25 & 36.223 .901 & 2000 & 18.111 .950 & 574 & 500 \\
\hline 17 & moyudan & Pasir volkanik sedang & 25 & 39.178 .132 & 2000 & 19.589 .066 & 621 & 500 \\
\hline
\end{tabular}

Penentuan nilai recharge air tanah dalam penelitian ini dipengaruhi oleh luas area tadah hujan dan curah hujan. Berdasarkan data penelitian di atas luas area berbanding lurus dengan imbuhan air tanah. Hal ini ditunjukkan dengan semakin tinggi curah hujan maka semakin tinggi 
pula imbuhan air tanah. Seperti perbandingan data pada daerah Tempel dengan Minggir yang memiliki luas area tadah hujan yang relatif sama yaitu $33.559 .736 \mathrm{~m}^{2}$ untuk Tempel dan $33.018 .592 \mathrm{~m}^{2}$ untuk Minggir tetapi memiliki perbedaan curah hujan yang cukup signifikan yaitu $2.675 \mathrm{~mm} /$ tahun untuk daerah Tempel dan $2187 \mathrm{~mm} /$ tahun untuk daerah Minggir. Didapatkan nilai imbuhan pada daerah Tempel adalah $802,5 \mathrm{~mm} /$ tahun sedangkan daerah Minggir lebih rendah yaitu $546,75 \mathrm{~mm} /$ tahun. Selanjutnya pada data penelitian tersebut juga dapat diketahui bahwa semakin besar luas area tadah hujan maka semakin tinggi pula imbuhan air tanah. Perbandingan data pada daerah Turi dengan Pakem menunjukan curah hujan yang sama yaitu $2750 \mathrm{~mm} /$ tahun tetapi memiliki perbedaan luas area tadah hujan yang signifikan yaitu $39.687 .966 \mathrm{~m}^{2}$ untuk daerah Turi dan $51.284 .863 \mathrm{~m}^{2}$ untuk daerah Pakem. Imbuhan pada daerah Turi adalah $1038 \mathrm{It} /$ detik (825 mm/tahun)sedangkan daerah Pakem lebih tinggi yaitu 1344lt/detik (825 mm/tahun).

Sehingga apabila dilihat dari kedua nilai recharge dari penelitian Victor Aleluia de Sousa Vicente (2014) dan pada penelitian Pemetaan dan Perhitungan Recharge Air Tanah Berdasarkan Data Curah Hujan di Kabupaten Sleman maka perbandingan nilai recharge dapat ditunjukan dengan grafik. Berikut ini adalah grafik perbandingan antara kedua data tersebut (Gambar 1) :

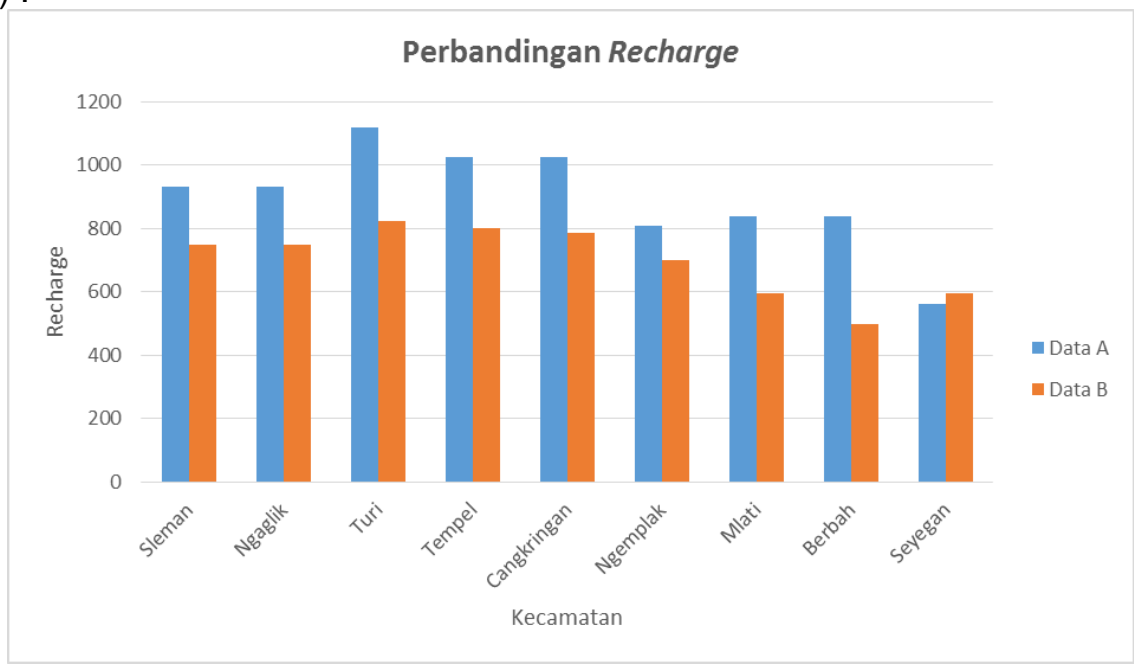

Gambar 1 Grafik perbandingan nilai recharge

Apabila dilihat dari grafik perbandingan nilai rechargeantara penelitian yang dilakukan Victor Aleluia de Sousa Vicente (2014) sebagai data B dengan penelitian Pemetaan dan Perhitungan Recharge Air Tanah Berdasarkan Data Curah Hujan di Kabupaten Sleman sebagai data A menunjukan kecenderungan data yang sama yaitu pada data curah hujan dan hasil recharge, yaitu semakin tinggi curah hujan disuatu daerah maka akan semakin tinggi pula recharge air tanah. Sebaliknya bila dilihat dari tingkat keakuratan data, maka lebih akurat pada penelitian yang dilakukan oleh Victor Aleluia de Sousa Vicente (2014). Hal ini dikarenakan pada penelitian Perhitungan Recharge Air Tanah Berdasarkan Data Curah Hujan di Kabupaten Sleman hanya menggunakan satu parameter yaitu curah hujan, sedangkan aspek luas area tadah hujan mempengaruhi data hasil recharge.

Berdasarkan dari perbandingan grafik diatas, dapat pula diketahui tingkat kesalahan dari penelitian Perhitungan Recharge Air Tanah Berdasarkan Data Curah Hujan di Kabupaten Sleman yang didasarkan dari data Victor Aleluia de Sousa Vicente (2014) dengan persamaan berikut ini (Donna Roberts, 2012) :

$$
\begin{aligned}
\text { Tingkat kesalahan } & =\frac{\text { Total data } A-\text { Total data } B}{\text { Tingtal data } B} \times 100 \% \\
& =28,402,4 \\
& =28,4
\end{aligned}
$$

Melalui persamaan di atas dapat diketahui bahwa tingkat kesalahan atau tingkat perbedaan antara penelitian Victor Aleluia de Sousa Vicente (2014) terhadap penelitian Perhitungan Recharge Air Tanah Berdasarkan Data Curah Hujan di Kabupaten Sleman yaitu sebesar 
$28,3 \%$ sehingga dapat dikatakan bahwa hasil penelitian ini masih relevan dan dapat diimplementasikan dengan baik.

\section{KESIMPULAN}

Hasil pengujian yang telah dilakukan didapatkan recharge air tanah tertinggi yaitu 1119,5 $\mathrm{mm} /$ tahun dengan curah hujan $2500 \mathrm{~mm} / \mathrm{tahun}$, sedangkan hasil perhitungan dari penelitian Victor Aleluia de Sousa Vicente yaitu 825 mm/tahun dengan curah hujan 2750 mm/tahun. Perbedaan hasil ini disebabkan karena parameter luas area tadah hujan dan litologi tanah yang digunakan pada penelitian Victor Aleluia de Sousa Vicente mempengaruhi hasil akhir recharge air tanah sehingga terdapat perbedaan hasil sebesar $28,3 \%$.

\section{Daftar Pustaka}

Bisson, Robert A., dan Lehr, Jay H., 2004, Modern Groundwater Exploration : Discovering New Water Resources in Consolidated Rocks Using Innovative Hydrogeologic Concepts, Exploration, Drilling, Aquifer Testing and Management Methods, ISBN 0-471-06460-2, John Wiley \& Sons, Inc.

Hatala, Nurleyla, 2007, Model Matematis Perubahan Kualitas Air Sungai di Daerah Aliran Sungai (DAS) Cisadane, Institut Pertanian Bogor.

Hendrayana, Heru, dan Aleluia, Victor de S. V., 2014, Cadangan Airtanah Berdasarkan Geometri dan Konfigurasi Sistem Akuifer Cekungan Airtanah Yogyakarta-Sleman, Jurusan Teknik Geologi Fakultas Teknik Universitas Gadjah Mada, Yogyakarta.

Ningsih, S., dan Ayuningtyas, E.A., 2011, Perhitungan Hasil Aman Untuk Batasan Pemompaan Airtanah, Universitas Gadjah Mada, Yogyakarta.

Yuhana, U. L., P., I G. L. A., Oka Cahyadi \& Fabroyir, H., 2010, Pemanfaatan Googlemaps Untuk Pemetaan dan Pencarian Data Perguruan Tinggi Negeri di Indonesia, Jurnal Sistem Informasi, Institut Teknologi Sepuluh Nopember, Surabaya. 